\title{
Behind the Technology: CT Perfusion in the Setting of Acute Stroke Management
}

\author{
Benjamin Zussman \\ Adam Flanders \\ Robert H. Rosenwasser MD \\ Thomas Jefferson University \\ Pascal Jabbour MD \\ Thomas Jefferson University
}

Follow this and additional works at: https://jdc.jefferson.edu/jhnj

\section{Let us know how access to this document benefits you}

\section{Recommended Citation}

Zussman, Benjamin; Flanders, Adam; Rosenwasser MD, Robert H.; and Jabbour, Pascal MD (2010)

"Behind the Technology: CT Perfusion in the Setting of Acute Stroke Management," JHN Journal: Vol. 5 :

Iss. 2 , Article 1.

DOI: https://doi.org/10.29046/JHNJ.005.2.001

Available at: https://jdc.jefferson.edu/jhnj/vol5/iss2/1

This Article is brought to you for free and open access by the Jefferson Digital Commons. The Jefferson Digital Commons is a service of Thomas Jefferson University's Center for Teaching and Learning (CTL). The Commons is a showcase for Jefferson books and journals, peer-reviewed scholarly publications, unique historical collections from the University archives, and teaching tools. The Jefferson Digital Commons allows researchers and interested readers anywhere in the world to learn about and keep up to date with Jefferson scholarship. This article has been accepted for inclusion in JHN Journal by an authorized administrator of the Jefferson Digital Commons. For more information, please contact: JeffersonDigitalCommons@jefferson.edu. 


\section{Behind the Technology: CT Perfusion in the Setting of Acute Stroke Management}

\author{
Benjamin Zussman, BS, ${ }^{1}$ Adam Flanders, MD, ${ }^{2}$ Robert Rosenwasser, MD, ${ }^{3}$ \\ Pascal Jabbour, $\mathrm{MD}^{3}$ \\ J Jefferson Medical College, Thomas Jefferson University, Philadelphia, PA \\ 2Department of Radiology, Thomas Jefferson University, Philadelphia, PA \\ 3Department of Neurological Surgery, Thomas Jefferson University, Philadelphia, PA
}

\begin{abstract}
Computed Tomography Perfusion (CTP) is an imaging modality that generates parametric maps of cerebral hemodynamics which are useful in the assessment of suspected acute ischemic stoke. However, the technology underlying CTP is complex and serious controversy surrounds the safety of CTP tests and the reproducibility and validity of CTP results. This report briefly outlines the history of CTP, its current clinical applications for stroke management, the main controversies surrounding CTP, and future directions for this technology.
\end{abstract}

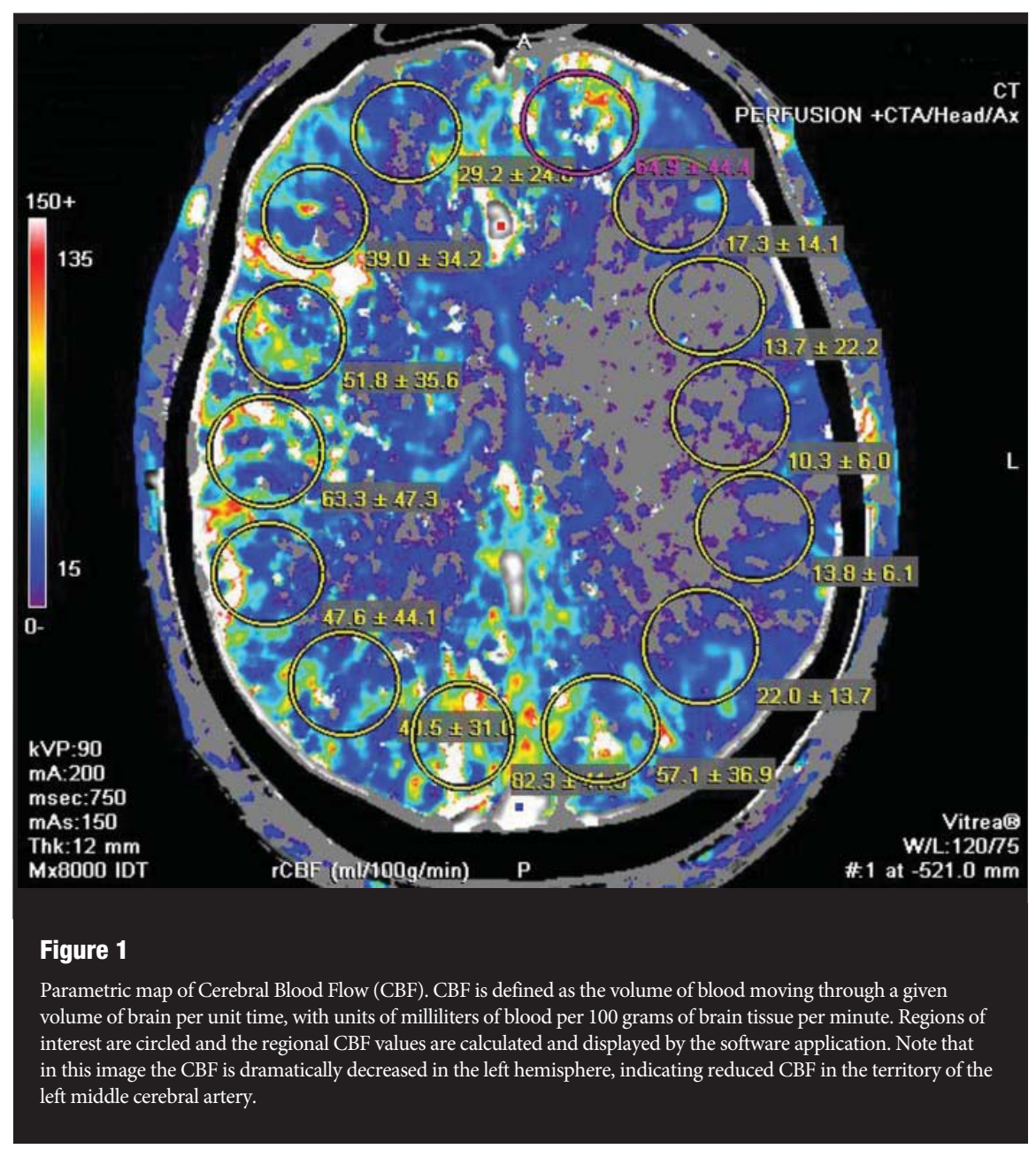

\section{Introduction}

In the setting of acute stroke, knowledge of the ischemic insult and potential for tissue salvage is critical in clinical decision-making. Dynamic, first-pass computed tomography perfusion (CTP) is an imaging modality that describes the hemodynamics of cerebral tissues. ${ }^{1}$ It does so by gathering information about the flow of contrast media through the cerebral vasculature and by calculating perfusion values that describe the blood flow through cerebral tissue beds. CTP is rapidly performed, ${ }^{2}$ commonly accessible, ${ }^{3}$ and when used alongside other imaging modalities such as non-contrast computed tomography (CT) and CT angiography, improves clinicians' diagnostic abilities in the setting of acute cerebrovascular attack. ${ }^{4}$

But several reports have demonstrated problems with CTP safety, ${ }^{5}$ reproducibility, ${ }^{6}$ and accuracy, ${ }^{7}$ which restrict the unique potential of CTP to produce quantitative perfusion results that are safely obtained and clinically meaningful. One factor that has limited the development of solutions to these problems may be the general confusion surrounding the technology, clinical applications, and controversies in CTP imaging. The purpose of this review was to briefly describe the history, current applications, controversies, and future directions of CTP in the context of acute stroke management.

\section{History of CTP}

In 1897 Stewart $^{8}$ introduced the indicatordilution theory for measurement of cardiac output and in 1954 Meier and Zierler ${ }^{9}$ built upon this work by presenting their theory of the indicator-dilution method for measurement of blood flow and volume, which states the basic relationship that, for a normal physiologic tissue bed, blood volume equals blood flow times the mean circulation time ( $\mathrm{V}=\mathrm{F} \times \mathrm{MT})$. In 1980 Axel ${ }^{10}$ first conceptualized the use of Computed Tomography (CT) in conjunction with a nondiffusible tracer to measure cerebral blood volume (CBV), cerebral blood flow (CBF), and mean transit time (MTT). Axel suggested that the central volume principles set forth by Meier and Zierler could be applied to CT-acquired data to successfully generate information about the blood flow in cerebral tissues. 
The recent development of high-speed helical or spiral CT scanners provided the machinery for CTP theory to be translated into practice. ${ }^{3}$ Furthermore, the development of computer software applications that process CT source images and generate perfusion maps enabled stroke management teams to simply and rapidly acquire cerebral perfusion data. ${ }^{11}$ Today, highspeed CT scanners are commonplace in U.S. hospitals and the entire CTP imaging process can be performed in a matter of minutes. ${ }^{2}$

\section{Current applications}

At our institution, patients who present with acute stroke symptoms are managed with a multi-pronged diagnostic algorithm. The first diagnostic test is always a non-contrast CT scan of the brain, which is used to rule-out cerebral hemorrhage, hematoma, and other lesions. Secondary tests include CT angiography and CTP. CT angiography examines the neck and head vasculature for vessel occlusion or rupture. This information is used to locate the pathology and determine whether endovascular treatments, such as thrombectomy, are warranted. CTP examines ischemic cerebral tissues and differentiates between irreversibly infarcted tissue, called the infarct core, and potentially salvageable tissue, called the penumbra.

It has been argued that infarct core has three characteristic features: (1) an elevated MTT (it takes more time for blood to traverse the ischemic tissue); (2) a reduced CBF (the velocity of blood flow through ischemic tissue is decreased); and (3) a reduced CBV (the volume of blood in the ischemic tissue is decreased). ${ }^{3}$ In

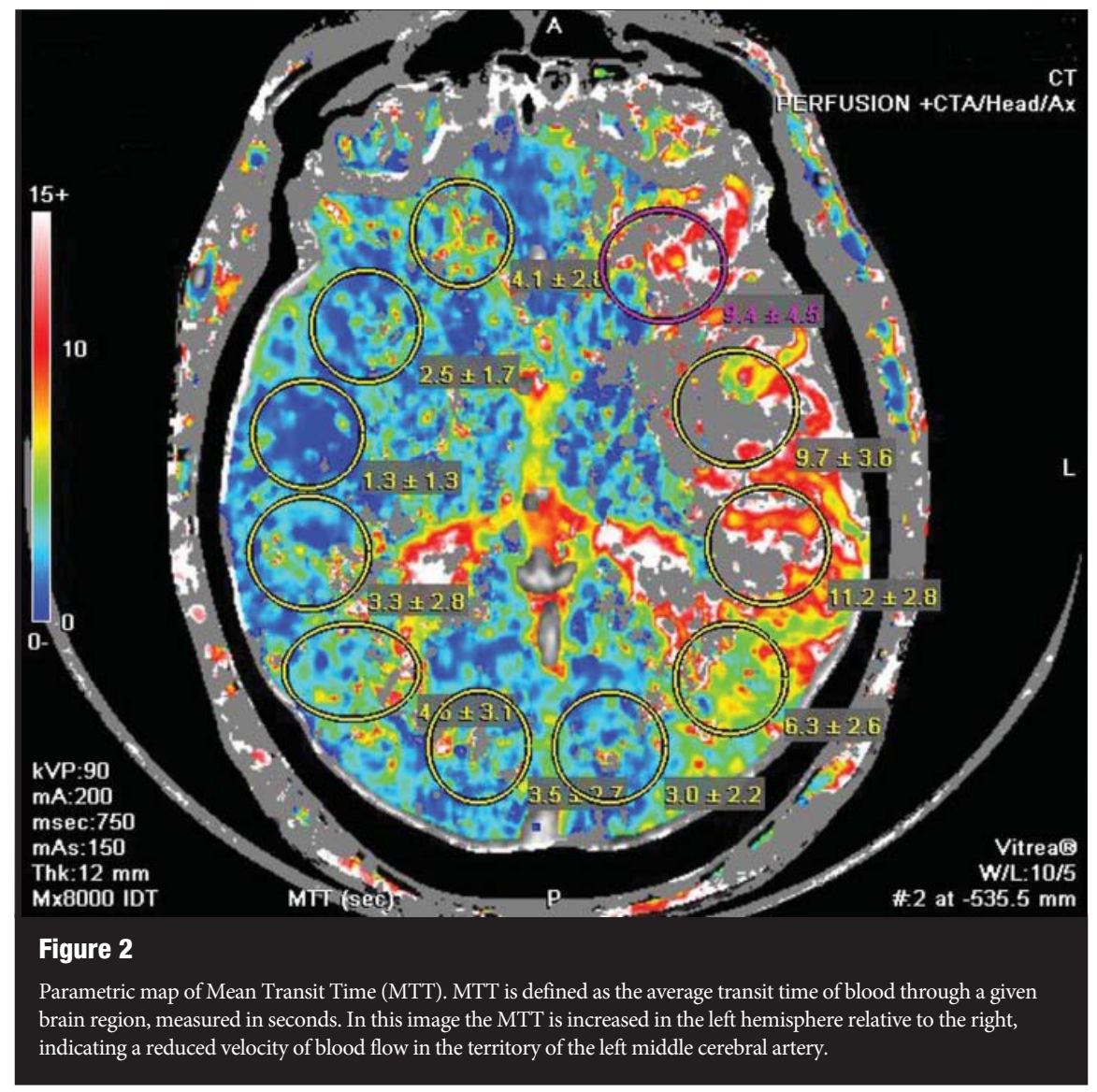

comparison, penumbra also demonstrates an elevated MTT and a reduced CBF. However, in penumbra the $\mathrm{CBV}$ is not reduced; it remains level or may even be elevated, due to collateral circulation via uninjured arterial and leptomeningeal territories. ${ }^{2}$ Thus, assuming that MTT is elevated and CBF is reduced, a mismatch in CBV may determine candidacy for

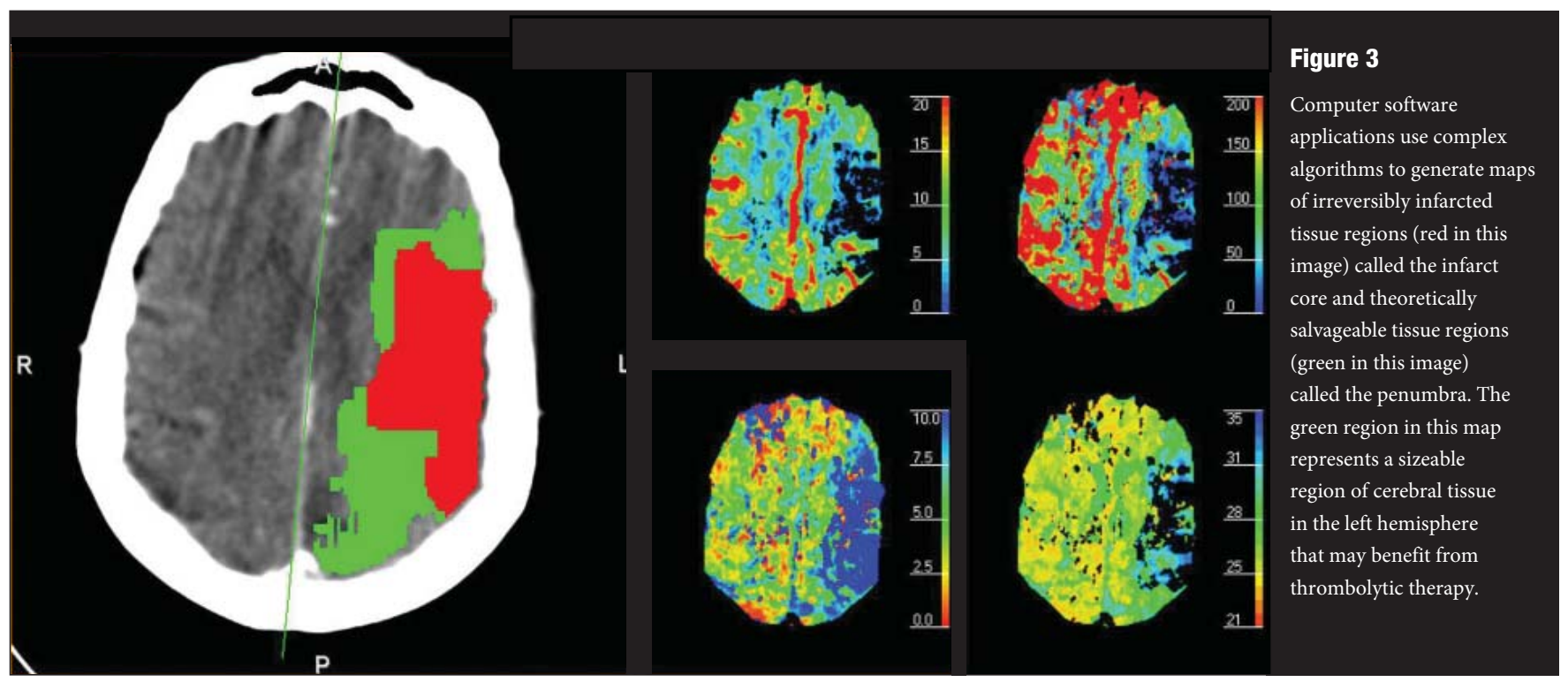


thrombolytic therapy, with a level or elevated CBV indicating treatment and a reduced CBV contraindicating treatment. ${ }^{3}$

Penumbra may be salvaged if blood flow restoration is rapidly achieved. Therapeutic agents, such as thrombolytics, aid clot dissolution and are considered when there is extensive penumbra. ${ }^{2}$ Yet the decision to use thrombolytic agents is not without risk as these medications may also induce severe hemorrhage. Therefore, the potential benefits of the recanalization of arteries supplying injured but salvageable tissue must be weighed against the potential morbidity and mortality associated with hemorrhage. ${ }^{3}$

Stroke management is a complex, teamoriented process. Image source data gathered in the Emergency Department by the CT scanner is transmitted over the computer network to neuroradiologists who process the data using commercial software applications to generate CTP parametric maps. These images are interpreted by neuroradiologists and are also passed to neurosurgeons. Dialogue between neuroradiologists, neurosurgeons, and neurologists consider all three studies-noncontrast CT, CT angiography, and CTP-to arrive at treatment decisions. Of course, effective communication between members of the stroke team and efficiency are paramount in the setting of acute stroke; as the saying goes, "time is brain."

\section{Controversies}

Several controversies surround CTP, including the risk of radiation exposure to patients. For instance, a July 2010 New York Times report ${ }^{5}$ highlighted the stories of scores of patients that have recently been exposed to radiation overdoses during CTP scans in hospitals across the U.S. On the other hand, the CTP radiation doses reported in the medical literature have generally been safe; as one review article stated, the radiation exposure in a typical CTP scan is approximately equal to the background radiation a person living in Boston, Massachusetts is exposed to in a given year. ${ }^{1}$ The radiation controversy partially hinges on the balance of radiation dose with image quality, and several authors ${ }^{12-14}$ have explored methods to achieve adequate image resolution and signal-to-noise while limiting radiation doses by altering the image acquisition frequency settings of CT scanners. This controversy also centers on the degree of automation that CT scanners use to calculate radiation doses; some experts argue that automation will lead to more appropriate dosing while others argue that unchecked automation may lead to unnecessary overdosing. ${ }^{5}$

Another controversy surrounding CTP is the variability of quantitative results. Studies have shown that multiple factors affect the perfusion maps that are generated by software applications. For example, software operator differences have led to significantly different perfusion results. ${ }^{6}, 15$ More recently, differences between software applications have been shown to generate significantly different results as well. ${ }^{7}$ Put differently, it is possible that identical source imaging data for a given patient will yield significantly different CTP results if processed by different operators or by different software applications. For these reasons, quantitative perfusion results have been traditionally interpreted with caution. Yet there is motive for improved reproducibility and accuracy of CTP results, because these values could be used to develop definitive perfusion thresholds for use in clinical decision-making, particularly the use of thrombolytic therapy, such as tissue plasminogen activator (tPA). ${ }^{16}$

\section{Future directions}

The stroke imaging community has identified two important steps for the improvement of CTP; standardization of CTP scanning and standardization of CTP post-processing. ${ }^{17}$ Progress is being made in both these aims. For instance, in September, 2007, consensus-based imaging acquisition protocols (including suggested radiation doses) for CTP were drafted at an international symposium of experts in the field. ${ }^{17}$ Additionally, efforts to improve the accuracy and reliability of CTP through the development of a digital phantom data set against which commercial software platforms can be evaluated are currently underway. ${ }^{18}$

\section{Conclusion}

CTP is a rapidly developing diagnostic imaging tool that is useful in acute stroke diagnosis. Standardization of this technology may enable clinical decision-making based on quantitative data.

\section{References}

1. Konstas AA, Goldmakher GV, Lee TY, Lev MH. Theoretic basis and technical implementations of CT perfusion in acute ischemic stroke, part 2: Technical implementations. AJNR Am J Neuroradiol. 2009 May;30(5):885-92.

2. Srinivasan A, Goyal M, Al Azri F, Lum C. State-of-the-art imaging of acute stroke. Radiographics. 2006 Oct;26 Suppl 1:S75-95.
3. Latchaw RE, Yonas H, Hunter GJ, Yuh WT, Ueda T, Sorensen AG, et al. Guidelines and recommendations for perfusion imaging in cerebral ischemia: A scientific statement for healthcare professionals by the writing group on perfusion imaging, from the council on cardiovascular radiology of the american heart association. Stroke. 2003 Apr;34(4):1084-104.

4. Hopyan J, Ciarallo A, Dowlatshahi D, Howard P, John V, Yeung R, et al. Certainty of stroke diagnosis: Incremental benefit with CT perfusion over noncontrast $\mathrm{CT}$ and $\mathrm{CT}$ angiography. Radiology. 2010 Apr;255(1):142-53.

5. Bogdanich W. After stroke scans, patients face serious health risks. The New York Times. 2010 July 31. Accessed at www. nytreprints.com.

6. Fiorella D, Heiserman J, Prenger E, Partovi S. Assessment of the reproducibility of postprocessing dynamic CT perfusion data. AJNR Am J Neuroradiol. 2004 Jan;25(1):97-107.

7. Kudo K, Sasaki M, Yamada K, Momoshima S, Utsunomiya $\mathrm{H}$, Shirato H, et al. Differences in CT perfusion maps generated by different commercial software: Quantitative analysis by using identical source data of acute stroke patients. Radiology. 2010 Jan;254(1):200-9.

8. Stewart, G. N. Researches on the circulation time and on the influences which affect it. IV. The output of the heart. J. Physiol. (London) 22:159-183, 1897.

9. Meier P, Zierler KL. On the theory of the indicator-dilution method for measurement of blood flow and volume. J Appl Physiol. 1954 Jun;6(12):731-44.

10. Axel L. Cerebral blood flow determination by rapid-sequence computed tomography: Theoretical analysis. Radiology. 1980 Dec;137(3):679-86.

11. Wintermark M, Maeder P, Thiran JP, Schnyder P, Meuli R. Quantitative assessment of regional cerebral blood flows by perfusion CT studies at low injection rates: A critical review of the underlying theoretical models. Eur Radiol. 2001;11(7):1220-30.

12. Wintermark M, Smith WS, Ko NU, Quist M, Schnyder P, Dillon WP. Dynamic perfusion CT: Optimizing the temporal resolution and contrast volume for calculation of perfusion CT parameters in stroke patients. AJNR Am J Neuroradiol. 2004 May;25(5):720-9.

13. Kloska SP, Fischer T, Sauerland C, Buerke B, Dziewas R, Fischbach $\mathrm{R}$, et al. Increasing sampling interval in cerebral perfusion CT: Limitation for the maximum slope model. Acad Radiol. 2010 Jan;17(1):61-6.

14. Kamena A, Streitparth F, Grieser C, Lehmkuhl L, Jamil B, Wojtal K, et al. Dynamic perfusion CT: Optimizing the temporal resolution for the calculation of perfusion CT parameters in stroke patients. Eur J Radiol. 2007 Oct;64(1):111-8.

15. Waaijer A, van der Schaaf IC, Velthuis BK, Quist M, van Osch MJ, Vonken EP, et al. Reproducibility of quantitative CT brain perfusion measurements in patients with symptomatic unilateral carotid artery stenosis. AJNR Am J Neuroradiol. 2007 May;28(5):927-32.

16. Wintermark M, Flanders AE, Velthuis B, Meuli R, van Leeuwen M, Goldsher D, et al. Perfusion-CT assessment of infarct core and penumbra: Receiver operating characteristic curve analysis in 130 patients suspected of acute hemispheric stroke. Stroke. 2006 Apr;37(4):979-85.

17. Wintermark M, Albers GW, Alexandrov AV, Alger JR, Bammer R, Baron JC, et al. Acute stroke imaging research roadmap. AJNR Am J Neuroradiol. 2008 May;29(5):e23-30.

18. Kudo K, Christensen S, Sasaki M, Ostergaard L. STIR-1 Digital Phantom Project. International Stroke Conference of the Stroke Imaging Repository (STIR), San Antonio, Texas, USA. February 25, 2010. 